\title{
The Synthesis of Hydroxybutyrate-Based Block Polyurethane from Telechelic Diols with Robust Thermal and Mechanical Properties
}

\author{
Dan Xue, ${ }^{1}$ Xiaodong Fan, ${ }^{1}$ Zengping Zhang, ${ }^{2}$ and Wei $\mathrm{Lv}^{3}$ \\ ${ }^{1}$ School of Science, Northwestern Polytechnical University, Xi'an, Shaanxi 710072, China \\ ${ }^{2}$ Key Laboratory for Special Area Highway Engineering of Ministry of Education, Chang'an University, \\ Xian, Shaanxi 710064, China \\ ${ }^{3}$ Oil and Gas Technology Research Institute, Changqing Oilfield Company, Xi'an, Shaanxi 710018, China \\ Correspondence should be addressed to Dan Xue; xdnwpu@163.com
}

Received 28 May 2016; Revised 19 August 2016; Accepted 24 August 2016

Academic Editor: Ewa Schab-Balcerzak

Copyright (C) 2016 Dan Xue et al. This is an open access article distributed under the Creative Commons Attribution License, which permits unrestricted use, distribution, and reproduction in any medium, provided the original work is properly cited.

\begin{abstract}
A series of novel amphiphilic block polyurethanes (PUHE) have been successfully synthesized by solution polymerization of the derived PHB-diol and poly(ethylene glycol) with a coupling agent of 1,6-hexamethylene diisocyanate (HDI), while the PHB-diol was prepared via the transesterification of PHB and ethylene glycol. The hydroxyl contents in PHB-diols range from 1.36 to 1.99 (the molar ratio) as determined by nonaqueous titration. The molecular weight and chemical compositions of PUHE and PHBdiol were investigated by GPC, ${ }^{1} \mathrm{H}$ NMR, and FTIR in detail, which confirm the successful synthesis of PUHE. The tensile strength and elongation at break of PUHE could reach as high as $20 \mathrm{MPa}$ and $210 \%$, as the content of PHB in PUHE is $33 \%$. TGA curves indicate that block-bonding between PHB-diol and PEG increases the thermal stability of PHB-diol. Film degradation of PUHE was studied by weight loss and scanning electron microscope (SEM). It could be concluded that degradation occurred gradually from the surface to the inside and that the degradation rate could be controlled by adjusting the PHB/PEG ratios. These properties make PUHE able to be used as a biodegradable thermoplastic elastomer.
\end{abstract}

\section{Introduction}

Polyhydroxybutyrate (PHB) originated from bacteria has been considered one of the most prospective bioplastics $[1,2]$ due to excellent strength close to that of isotactic polypropylene and favorable melt processability $[3,4]$ for conventional process, such as extrusion $[5,6]$, moulding $[7,8]$, and spinning $[9,10]$. Therefore, PHB is widely used in the fields of food packaging [11], tissue engineering [12], drug delivery, and so forth [13-15]. However, it should be mentioned that the application of PHB is greatly limited by the brittleness, high hydrophobicity [16-18], and the narrow processing window $[19,20]$. Thus, many attempts have been developed to improve the properties of $\mathrm{PHB}$, including the preparation of block or graft copolymers or blending with suitable polymers [21-26]. Among them, block copolymerization is regarded as a simple and effective approach.
Polyurethane elastomer is a kind of block copolymer composed of soft and hard segments [27-29], which can be synthesized by the reaction between polymer terminated with free hydroxyl groups and difunctional isocyanates [3034]. And the easy control over the domain structure of polyurethanes through the selection of monomer units makes it superior to other kinds of PHB material. In the synthesis of polyurethane elastomer, mole ratio of $\mathrm{NCO} / \mathrm{OH}$ shows a significant effect on the mechanical and hydrophilic performance. As $\mathrm{NCO} / \mathrm{OH}$ molar ratio increases, the proportion of hard segments of polyurethane will increase leading to a decrease of the flexibility of chain. Meanwhile, the increase of $\mathrm{NCO} / \mathrm{OH}$ molar ratio results in an increase in the number of hydrogen bonds, which leads to an increase in crosslink density (hydrogen bonds formed from the cross-linking); thus, the hydrophobicity of polyurethane will increase accordingly. NCO content could be accurately determined by chemical 
analysis method [35]. However, few researches focus on the measurement of the content of free hydroxyl groups.

PHB oligomers terminated with free hydroxyl groups may be produced by the transesterification of alkane-diols with high molecular weight of PHB. Saad et al. synthesized macrodiols by transesterification of PHB in 1,2dichloroethane with 1,10-decanediol and $p$-toluenesulfonate as catalysts [36]. Hirt et al. obtained telechelic dihydroxy$\mathrm{PHB}$ by glycolysis of bacterial derived high molecular weight dihydroxy-PHB [37]. However, it is still a challenge to quantify the terminal hydroxyl content in $\mathrm{PHB}$ oligomers and to study its effect on properties of the corresponding polyurethanes.

Herein, a promising polyurethane elastomer was synthesized by solution polymerization of PHB-diol and poly(ethylene glycol) with a coupling agent of 1,6-hexamethylene diisocyanate (HDI). While the PHB-diol was prepared via the transesterification of PHB with ethylene glycol, the hydroxyl content of PHB-diol was quantified by the titration of acetic anhydride-pyridine. Then chemical compositions were investigated with GPC, ${ }^{1} \mathrm{H}$ NMR, and FTIR in detail. The relationship between block structure and degradation profiles was performed. Furthermore, the thermal and mechanical properties of as-prepared PUHE were studied to exploit its potential application as thermoplastic biodegradable elastomer.

\section{Experimental}

2.1. Materials. Polyhydroxybutyrate (PHB, Mn of $7.0 \times 10^{5} \pm$ $10 \% \mathrm{~g} / \mathrm{mol}$ ) was purchased from Zhejiang Tianan Tech Co. Ltd. (Zhejiang, China). All PHB samples were purified by dissolving in chloroform followed by filtration and precipitation in ether before use. 1,6-Hexamethylene diisocyanate (HDI) (99\%, Sigma, USA) was used without further purification. Chloroform, p-toluenesulfonic acid (PTSA), and ethylene glycol were all from Kemiou Reagent Development Center (Tianjin, China) and were used as received.

\subsection{Preparation of Dihydroxy-Terminated PHB Oligomers} (PHB-Diol). Dihydroxyl-terminated PHB oligomers (PHBdiol) were prepared by transesterification between the purified $\mathrm{PHB}$ materials and ethylene glycol using $p$ toluenesulfonic acid as catalyst [38-40]. Typically, purified PHB (10 g) was dissolved in $100 \mathrm{~mL}$ of chloroform and refluxed in nitrogen. Subsequently $p$-toluenesulfonic acid $(4.8 \mathrm{~g})$ and ethylene glycol $(20 \mathrm{~g})$ were added. The reaction temperature was controlled at $60^{\circ} \mathrm{C}$. The reaction was carried out under reflux for $6 \sim 10 \mathrm{~h}$ depending on required molecular weight of PHB-diol. The resultant solution was washed with distilled water for 3 times, concentrated, and dried under reduced pressure.

2.3. Hydroxyl Titration. Nonaqueous titration was employed to determine the hydroxyl content in PHB oligomers [41]. $0.10 \mathrm{~g}$ of $\mathrm{PHB}$ oligomers was added to $5 \mathrm{~mL}$ solution of acetic anhydride in pyridine $(2.0 \% \mathrm{v} / \mathrm{v})$ and then heated up to $100^{\circ} \mathrm{C}$ for acetylation of $1 \mathrm{~h}$. After that, $1 \mathrm{~mL} \mathrm{H}_{2} \mathrm{O}$ was added to the reaction mixture that was left alone for another $0.5 \mathrm{~h}$. The solution of $\mathrm{KOH}$ in methanol $(2.0 \mathrm{~g} / \mathrm{L})$ was used to titrate the reaction mixture in which several drops of thymol blue/cresol red solution $(3 / 1,0.4 \% \mathrm{w} / \mathrm{v})$ were added as the indicator. The blank titrating experiment without $\mathrm{PHB}$ oligomers followed the same procedure as above.

2.4. PHB-PEG Urethane Preparation. A series of polyurethanes (PUHE) were synthesized by different molar ratios of polyethylene glycol $(\mathrm{Mn}=1500 \mathrm{~g} / \mathrm{mol})$ and PHB-diols with different molecular weight. $1.8 \mathrm{~g}$ of $\mathrm{PHB}$-diol and polyethylene glycol were dried in a $25 \mathrm{~mL}$ two-necked tube at $40^{\circ} \mathrm{C}$ under vacuum overnight. Then, $20 \mathrm{~mL}$ of anhydrous 1,2-dichloroethane was added to the flask, and any trace of water in the system was removed through azeotropic distillation with only $5 \mathrm{~mL}$ of 1,2-dichloroethane being left in the flask. When the flask was cooled down to $75^{\circ} \mathrm{C}, 0.20 \mathrm{~g}$ of HDI $\left(1.2 \times 10^{-3} \mathrm{~mol}\right)$ and two drops of tin octoate $\left(8 \times 10^{-3} \mathrm{~g}\right)$ were added sequentially. The reaction mixture was stirred at $80^{\circ} \mathrm{C}$ under nitrogen atmosphere for $48 \mathrm{~h}$. The resultant copolymer was precipitated in diethyl ether and further purified in a mixture of methanol and diethyl ether.

2.5. ${ }^{1} H$ NMR Spectrum. The chemical structure and monomer composition were determined by ${ }^{1} \mathrm{H}$ NMR using a ADVANCEIII $400 \mathrm{MHz}$ NMR spectrometer. The NMR spectrum was obtained at room temperature in $\mathrm{CDCl}_{3}$ $(20 \mathrm{mg} / \mathrm{mL})$ with tetramethylsilane (TMS) as an internal standard.

2.6. Fourier Transform Infrared (FTIR) Spectroscopy. Fourier transform infrared (FTIR) spectroscopy was measured by a Bio-Rad FTS135 (Bio-Rad, USA) spectrophotometer. PHBco-PEG block polyurethane (PUHE) was dissolved in chloroform, coated on a $\mathrm{KBr}$ pellet, and dried before test.

2.7. Gel Permeation Chromatography. Average molecular weights were determined by gel permeation chromatography (GPC) using chloroform as an eluent at a flow rate of $1.0 \mathrm{~mL} / \mathrm{min}$ in Waters 1525 pump with a combination of four Styragel columns series (Styragel HR, $5 \mathrm{~mm}$ ) and equipped with a 2414 differential refractive index detector and UV detector (Agilent Technologies PL-GPC 50 Integrated GPC System, USA). The sample concentration was $2 \mathrm{mg} / \mathrm{mL}$ and $150 \mu \mathrm{L}$ of the injection volume. The calibration curve was obtained using polystyrene standards (Shodex, Japan). All samples were carried out with 64 scans at a resolution of $2 \mathrm{~cm}^{-1}$ at room temperature.

2.8. Differential Scanning Calorimetry (DSC) Measurements. Differential scanning calorimetry (DSC) measurements were performed on TA Instruments Q100 differential scanning calorimeter equipped with an auto-cool accessory and calibrated using indium. The following protocol was used for each sample: heating from room temperature to $150^{\circ} \mathrm{C}$ at a heating rate of $5^{\circ} \mathrm{C} / \mathrm{min}$, holding at $150^{\circ} \mathrm{C}$ for $3 \mathrm{~min}$, cooling from 150 to $-50^{\circ} \mathrm{C}$ at a heating rate of $5^{\circ} \mathrm{C} / \mathrm{min}$, being isothermal at $-50^{\circ} \mathrm{C}$ for $3 \mathrm{~min}$, and finally reheating from -50 


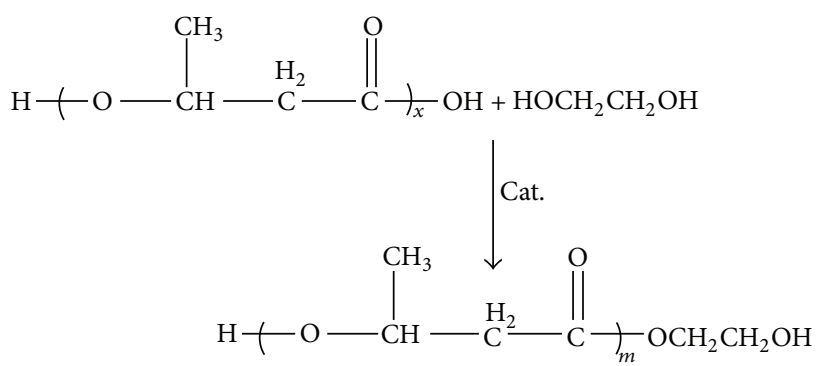

SCHEME 1: Synthesis of PHB oligomer.

to $150^{\circ} \mathrm{C}$ at a heating rate of $5^{\circ} \mathrm{C} / \mathrm{min}$. Data collected from both first cooling and second heating runs were analyzed and peak maxima were taken as transition temperatures.

2.9. Thermogravimetric Analysis. Thermogravimetric analysis (TGA) was carried out on TA Instruments SDT 2960. Samples were heated at $20^{\circ} \mathrm{C} / \mathrm{min}$ from room temperature to $500^{\circ} \mathrm{C}$ in a dynamic nitrogen atmosphere (flow rate $70 \mathrm{~mL} / \mathrm{min})$.

2.10. Mechanical Property. The tensile experiment was conducted on a WD-10E electronic universal tensile machine (made in Changchun Second Material Experiment Factory, type: WD-10E) at room temperature with the loading speed of $2 \mathrm{~mm} / \mathrm{min}$.

2.11. Degradation Experiments. Copolymer films were prepared by solvent casting from a $10 \mathrm{wt} \%$ chloroform solution. The resultant films were dried in vacuo at $50^{\circ} \mathrm{C}$ for 2 days, cut into discs (diameter, $25 \mathrm{~mm}$; thickness, $2 \mathrm{~mm}$ ), and used for the degradation experiments. The polymer films (approx. $200 \mathrm{mg}$ ) were placed in small bottles containing $10 \mathrm{~mL}$ buffer solution ( $\mathrm{pH} 7.4$ ) under a constant temperature of $37^{\circ} \mathrm{C}$. The PBS buffer solution contained $8.0 \mathrm{~g} \mathrm{NaCl}, 0.2 \mathrm{~g} \mathrm{KCl}$, $1.44 \mathrm{~g} \mathrm{Na}_{2} \mathrm{HPO}_{4}$, and $0.24 \mathrm{~g}$ of $\mathrm{KH}_{2} \mathrm{PO}_{4}$ in $1 \mathrm{~L}$ solution. Buffer solution in small bottles was renewed every 2 weeks, and samples were removed periodically, washed with distilled water, and subsequently dried in vacuum to a constant weight before analysis.

The weight loss of the polymer films after degradation was evaluated with residual weight (\%), which was defined by

$$
\text { Residual Weight }(\%)=\left(\frac{w_{t}}{w_{0}}\right) \times 100 \% \text {, }
$$

where $w_{0}$ and $w_{t}$ were the initial weight and the weight at time $t$, respectively. $w_{t}$ was obtained after drying the samples at $50^{\circ} \mathrm{C}$ under vacuum for 1 week.

2.12. Scanning Electron Microscopy (SEM). The microscopic morphology of the $\mathrm{PHB}$ and PUHE copolymers during degradation was also investigated with SEM (Hitachi X-650, Japan). For the morphological measurements, the samples were coated with gold to provide conductive surfaces.

\section{Results and Discussion}

3.1. Synthesis of PHB-co-PEG Block Polyurethane (PUHE) and Its Oligomer. As described in the experimental part, dihydroxyl-terminated $\mathrm{PHB}$ oligomers (PHB-diols) were obtained through transesterification between high molecular weight natural $\mathrm{PHB}$ and ethylene glycol using $p$ toluenesulfonic acid as catalyst.

The synthetic schematic route of the controlled alcoholysis of bacterial PHB is shown in Scheme 1. As shown in Scheme 1, the ethylene glycol broke the ester bond, producing the double-hydroxyl terminated product. Since the alcoholysis proceeds according to a random cleavage mechanism, the molecular weight of the degraded product decreases rapidly at the initial stage. As the reaction continues, the decreasing rate will fall.

PUHE was synthesized by the solution polymerization between PHB-diol and polyethylene glycol at $80^{\circ} \mathrm{C}$, and HDI was chain extender in the reaction system. Because the reaction is moisture-sensitive, azeotropic distillation was carried out to remove any trace of water in the system before HDI was added in. HDI was carefully dropped into the stirring reaction mixture at 1 drop/10 min to keep the homogeneous reactants and prevent the insoluble byproducts as less as possible. And the reaction proceeded in dried 1,2-dichloroethane under a nitrogen atmosphere. The target polyurethane PUHE was isolated and purified from the reaction mixture by repeated precipitation from a mixture of methanol and diethyl ether. The reaction process is shown in Scheme 2. In the molecular chain of PUHE, PHB acts as hard segment and PEG acts as soft segment, with HDI as a coupling agent, and many urethane groups (-NH-COO-) are across the molecular chain. A number of hydrogen bonds can be formed between - $\mathrm{NH}$ and -CO-groups acting as crosslinking bonds for the linear molecular chains to assemble into a physical crosslinked network, which endows the synthetic segmented copolymer a certain degree of toughness.

\subsection{Effects of Alcoholysis on Molecular Weight and Thermal} Properties of PHB-Diols. DSC is a useful measurement for estimation of the thermal transition of PHB-diols. Melting temperature $\left(T_{m}\right)$ and melting enthalpy $\left(\Delta H_{m}\right)$ of PHB-diol can be obtained from the DSC curves, as listed in Table 1 . The reaction conditions, $\mathrm{Mn}, \mathrm{Mw} / \mathrm{Mn}$, and other characteristics of the PHB-diols are also presented in Table 1. The PHB-diols are denoted as PHB I, PHB II, PHB III, and PHB IV for 


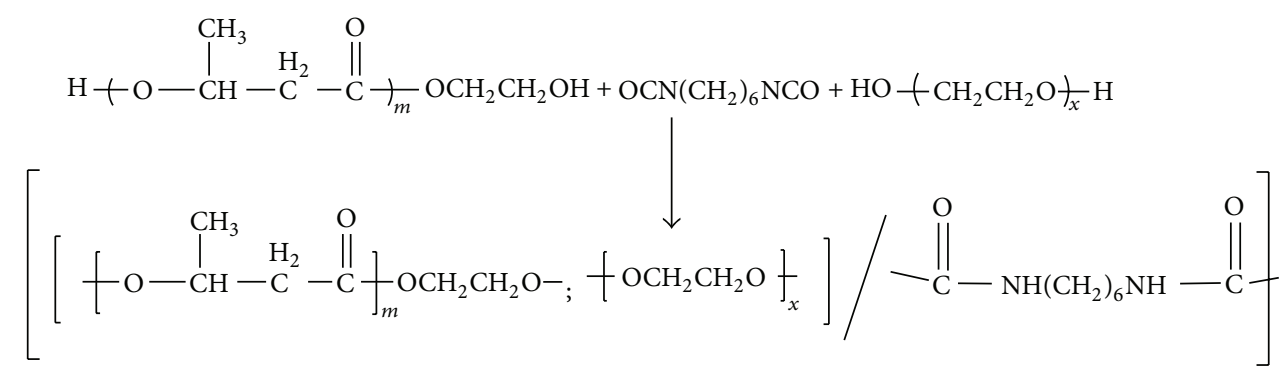

ScHeme 2: Synthesis of PHB-co-PEG block polyurethane (PUHE).

TABLE 1: Reaction conditions, thermal and molecular weight characteristics of PHB-diols.

\begin{tabular}{|c|c|c|c|c|c|c|c|c|}
\hline Sample & $\begin{array}{c}\text { Alcoholysis } \\
\text { time (h) }\end{array}$ & $\begin{array}{c}\mathrm{Mn}^{\mathrm{a}} \\
\left(\times 10^{3} \mathrm{~g} / \mathrm{mol}\right)\end{array}$ & $\begin{array}{c}\mathrm{Mw}^{\mathrm{a}} \\
\left(\times 10^{3} \mathrm{~g} / \mathrm{mol}\right)\end{array}$ & $\mathrm{Mw} / \mathrm{Mn}^{\mathrm{a}}$ & $T_{m}{ }^{\mathrm{b}}\left({ }^{\circ} \mathrm{C}\right)$ & $\Delta H_{m}{ }^{\mathrm{c}}(\mathrm{J} / \mathrm{g})$ & $X_{c}{ }^{\mathrm{d}} \%$ & $\begin{array}{l}\text { Hydroxyl content } \\
\text { (molar ratio) }\end{array}$ \\
\hline PHB & - & 70 & & & 175 & 71.86 & 49.0 & \\
\hline PHB I & 1 & 21.7 & 34.7 & 1.59 & 169.5 & 71.74 & 48.9 & 1.99 \\
\hline PHB II & 5 & 6.98 & 12.1 & 1.74 & 156.4 & 68.57 & 46.8 & 1.36 \\
\hline PHB III & 6 & 6.18 & 9.72 & 1.57 & 156.2 & 55.9 & 38.1 & 1.97 \\
\hline PHB IV & 8 & 4.42 & 7.33 & 1.66 & 158.3 & 34.38 & 23.5 & 1.92 \\
\hline
\end{tabular}

${ }^{\mathrm{a}} \mathrm{Mn}, \mathrm{Mw}$, and polydispersity (Mw/Mn) were determined by GPC (in $\mathrm{g} / \mathrm{mol}$ ).

${ }^{\mathrm{b}}$ Melt point $T_{m}$ was from the DSC second heating run.

${ }^{c}$ Melting enthalpy was calculated from the endothermal peak in the DSC second heating run.

${ }^{\mathrm{d}}$ Crystallinity calculated from the melting enthalpy in DSC second heating run. Reference value of $100 \%$ crystallized PHB was $\Delta H_{m}{ }^{\theta}=146 \mathrm{~J} / \mathrm{g}$ and $X_{c} \%=$ $100 \times \Delta H_{m} / \Delta H_{m}{ }^{\theta}$.

PHB-diols with Mn of $21700 \mathrm{~g} / \mathrm{mol}, 6980 \mathrm{~g} / \mathrm{mol}, 6180 \mathrm{~g} / \mathrm{mol}$, and $4420 \mathrm{~g} / \mathrm{mol}$ prepared with various alcoholysis time, respectively. It is noticeable that melting temperature and melting enthalpies of PHB-diol decrease with the increase of the alcoholysis time. It can be observed from Table 1 that the $T_{m}$ values of PHB-diols are directly related to the molecular weight. $T_{m}$ of PHB-diol decreases by approximately $17^{\circ} \mathrm{C}$ as $\mathrm{Mn}$ decreases to $4,420 \mathrm{~g} / \mathrm{mol}$ compared with precursor. The relatively high enthalpy of melting $\left(\Delta H_{m}\right)$ of the PHB-diols indicates a high degree of crystallinity. Based on the reported value for the heat of melting of $100 \%$ crystalline PHB (146 J/g) [24], the degree of crystallinity for our samples was calculated to be in the range of 23.5 48.9\%. The lowered $X_{c}$ and $T_{m}$ of PHB-diols compared to the precursors might be due to the presence of ethylene glycol restricting the crystallization of the PHB.

GPC is employed to determine the molecular weight and its distribution of PHB-diol. The results are listed in Table 1. It shows that the molecular weight of PHB-diol declined quickly in the initial $5 \mathrm{~h}$ of alcoholysis reaction. The $\mathrm{Mn}$ was $21.7 \times 10^{3} \mathrm{~g} / \mathrm{mol}$ after $1 \mathrm{~h}$ alcoholysis. When the reaction time reached $5 \mathrm{~h}, \mathrm{Mn}$ was decreased by almost two orders of magnitude compared with precursor, reduced to $6.98 \times$ $10^{3} \mathrm{~g} / \mathrm{mol}$. The decreasing rate of Mn slowed down when the reaction time exceeds $5 \mathrm{~h}$. All of PHB-diols show the narrow molecular weight distribution despite undergoing different reaction time $(\mathrm{Mw} / \mathrm{Mn}=1.59 \sim 1.74)$.

3.3. The Hydroxyl Contents in PHB Oligomers. Higher $\mathrm{NCO} / \mathrm{OH}$ molar ratio in PUHE yields a high crosslinking degree resulting in rigid and brittle copolymer, which makes it difficult to the subsequent processes. In this study, nonaqueous titration was employed to quantify the terminal hydroxyl content. The molar ratio of PHB to PEG was fixed at $1: 1$ in the synthesis of PUHE. The amount of HDI was equivalent to that of the reactive hydroxyl groups in the solution. The hydroxyl contents in PHB-diol range from 1.36 to 1.99 determined by nonaqueous titration, as shown in Table 1, which are in good agreement with the calculated values.

3.4. Characterization of Infrared Spectroscopy. To investigate the compositions of as-prepared PHB-diol and PUHE elastomer, FTIR is employed as shown in Figure 1. It is confirmed by the band at $3435 \mathrm{~cm}^{-1}$ corresponding to the hydrogen-bonded hydroxyl groups with alkoxy, and this band appears in the spectrum of PHB-diol while it appears very weak in that of original PHB. As shown in Figure 1(c), the band near $3435 \mathrm{~cm}^{-1}$ attributed to bonded -NH-groups is overlapped with hydrogen-bonded hydroxyl groups with PEG, and absorption peak becomes more distinct. The band near $1723 \mathrm{~cm}^{-1}$ corresponds to $\mathrm{C}=\mathrm{O}$ stretching modes. The amide absorption at $1546 \mathrm{~cm}^{-1}$ is the characteristic peak of urethane, which demonstrates the copolymerization between PHB and PEG.

3.5. Characterization of Proton Nuclear Magnetic Resonance Spectra $\left({ }^{1} H\right.$ NMR). The NMR spectra of PHB-diols are shown in Figure 2, ${ }^{1} \mathrm{H}$ NMR $\left(\mathrm{CDCl}_{3}\right): 5.21-5.29$ (due to protons $\mathrm{b}$ ), 4.21-4.23 (due to protons $\mathrm{b}^{\prime}$ and $\mathrm{e}$ ), 3.81 (due to protons d), 2.41-2.66 (due to protons a and $\left.\mathrm{a}^{\prime}\right), 1.22-1.32$ (due to protons $\mathrm{c}$ ), and 1.16 (due to protons $\mathrm{c}^{\prime}$ ). This proved that the hydroxyl-terminated PHB oligomers were produced successfully. 
TABLE 2: Compositions and molecular weights of resulting PUHE copolymers.

\begin{tabular}{lccccr}
\hline Sample & $F_{\text {PHB }}(\%)$ & $F_{\text {PEG }}(\%)$ & $F_{\text {HDI }}(\%)$ & Mn $(\mathrm{g} / \mathrm{mol})$ & \multicolumn{2}{c}{ Molecular weight } \\
Mw (g/mol) & 27635 & 40585 \\
\hline PUHE-1 & 87.3 & 11.4 & 1.3 & 18237 & 29201 \\
PUHE-2 & 84.8 & 13.7 & 1.5 & 17370 & 1.47 \\
PUHE-3 & 80.6 & 16.5 & 2.9 & 26382 & 1.60 \\
\hline
\end{tabular}

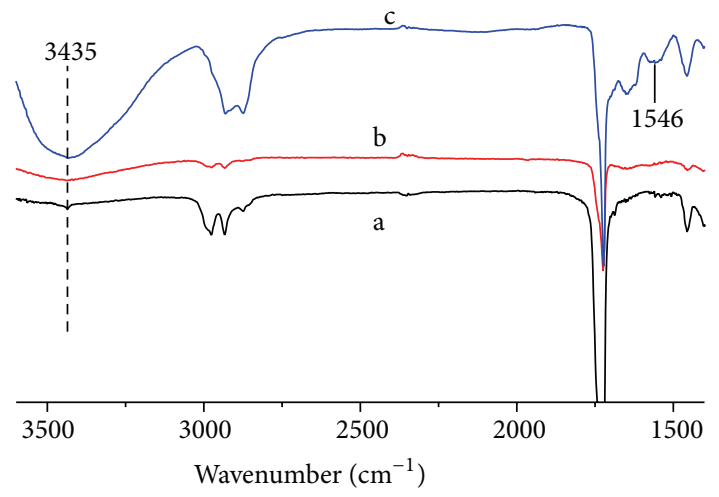

Figure 1: FTIR spectra of (a) PHB, (b) PHB-diol, and (c) PUHE.

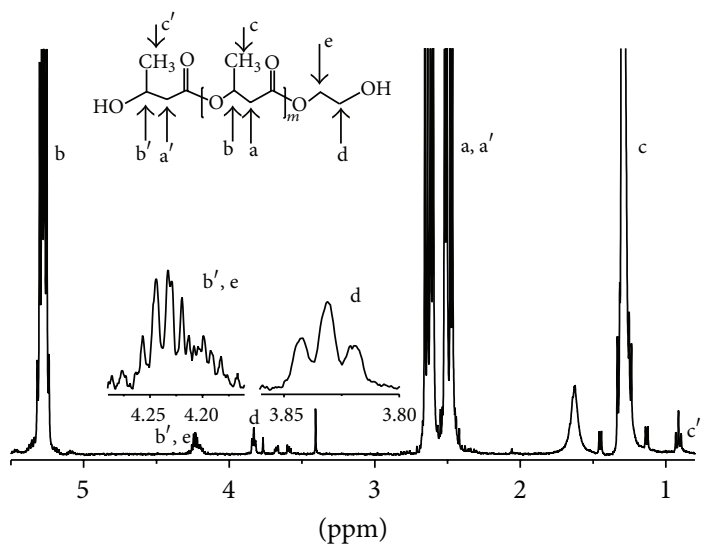

Figure 2: ${ }^{1} \mathrm{H}$ NMR spectra of PHB-diol.

The ${ }^{1} \mathrm{H}$ NMR $\left(\mathrm{CDCl}_{3}\right)$ spectra of polyurethanes (PUHE) are shown in Figure 3: 5.21-5.29 (due to protons b), 4.93 (due to protons a and $\mathrm{a}^{\prime}$ ), 4.20 (due to protons $\mathrm{f}$ and $\mathrm{f}^{\prime}$ ), 1.26 (due to protons c), 2.44-2.63 (due to protons d), 3.17 (due to protons $\mathrm{g}$ and $\mathrm{g}^{\prime}$ ), 3.66 (due to protons e, $\mathrm{e}^{\prime}, \mathrm{f}$, and $\mathrm{f}^{\prime}$ ), 1.48 (due to protons $h$ and $h^{\prime}$ ), and 1.32 (due to protons $i$ and $i^{\prime}$ ).

3.6. Compositions and Molecular Weights of PUHE Copolymers. In order to overcome the brittleness of PHB based block copolymer, a short PHB segment in PUHE is required to reduce the crystallinity. Herein, PHB content in the block copolymers could be tuned by adjusting the molar ratio of PHB-diol and PEG. Three series of PUHE were synthesized from PEG with Mn of $1500 \mathrm{~g} / \mathrm{mol}$ and PHB-diols with $\mathrm{Mn}$ of $6180 \mathrm{~g} / \mathrm{mol}$, respectively. The compositions of PUHE could be calculated by comparing the integration value of resonances at $\delta=5.25 \mathrm{ppm}$ assigned to methine in repeating units of PHB block and that at $\delta=3.66 \mathrm{ppm}$ assigned to methylene

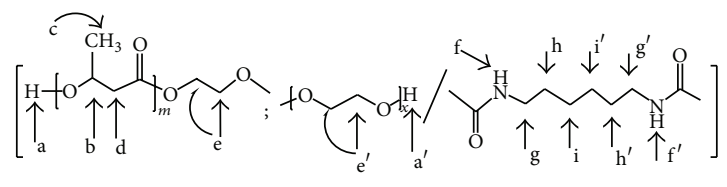

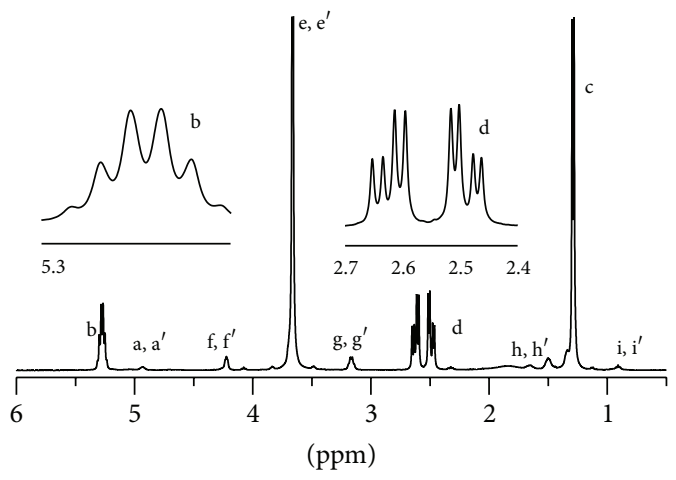

FIGURE 3: ${ }^{1} \mathrm{H}$ NMR spectra of polyurethane PUHE.

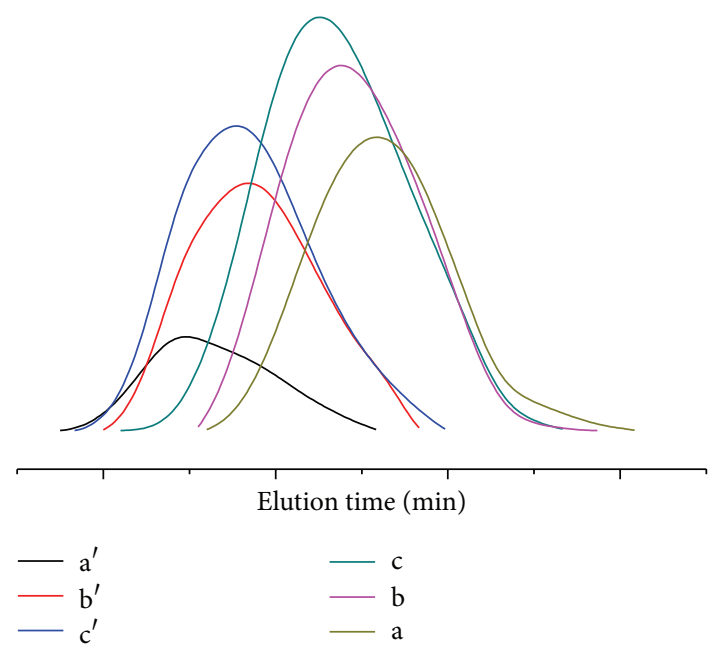

FIgURE 4: GPC diagrams of PHB-diols ( $a, b, c)$ and PUHE copolymers $\left(\mathrm{a}^{\prime}, \mathrm{b}^{\prime}, \mathrm{c}^{\prime}\right)$. (a) Reaction time: $8 \mathrm{~h}$; (b) reaction time: $6 \mathrm{~h}$; (c) reaction time: $5 \mathrm{~h}$.

in repeating units of PEG block. The compositions of the polymers are presented in Table 2. As is shown from Table 2, the molecular weight of PUHE gradually declines with the decrease of PHB-diol content.

3.7. Characterization of Gel Permeation Chromatography. GPC chromatograph was taken to measure the molecular weight of PHB-diols and block copolymers. Figure 4 shows 


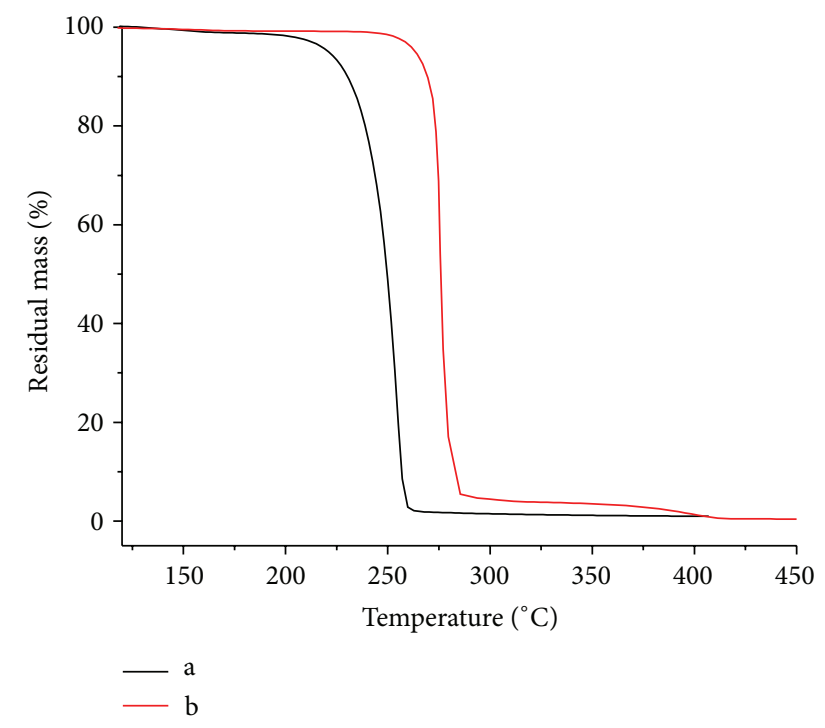

Figure 5: TGA curves of PHB-diol (a) and PUHE (b).

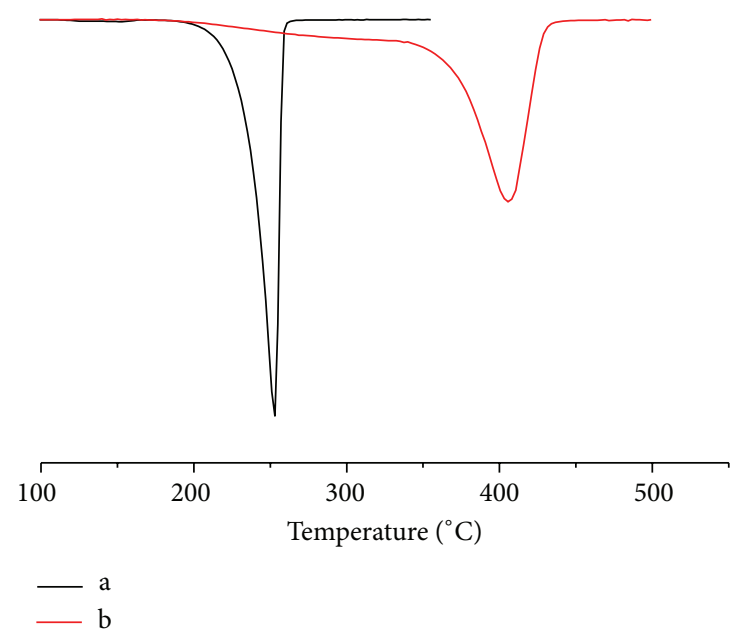

Figure 6: DTG curves of PHB-diol (a) and PUHE (b).

the typical GPC curves of the block copolymers as compared with those of PHB-diols. In GPC chromatograph, the unimodal peaks of the purified polyurethanes PUHE with nonoverlapping compared with those of corresponding precursors indicate that a complete reaction took place with no unreacted precursor remaining. All the polyurethanes PUHE showed narrow molecular weight distribution with polydispersity ranging from 1.47 to 1.60 and high molecular weight with $\mathrm{Mn}$ from $1.73 \times 10^{4} \mathrm{~g} / \mathrm{mol}$ to $2.76 \times 10^{4} \mathrm{~g} / \mathrm{mol}$. It shows that the peaks of block copolymers are shifted toward a high molecular weight region compared with that of the original PHB-diols. Together with the results of FTIR and ${ }^{1} \mathrm{H}$ NMR, this confirms the successful synthesis of PUHE by PHB-diol and PEG via the solution polymerization.

3.8. Thermal Properties. Thermal stability of polymers plays a crucial role in the determination of their working temperature and the application conditions. Figures 5 and 6 show

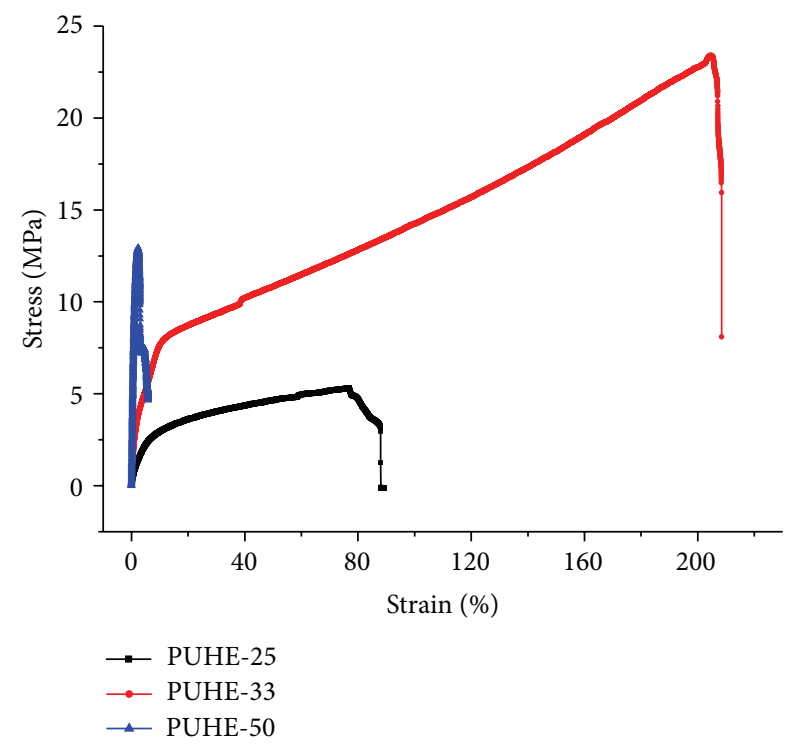

FIgURE 7: Typical stress-strain curves of PUHE with different composition.

the typical TGA curves and the corresponding differential thermogravimetric (DTG) curves of PHB-diol and PUHE, respectively. The degradation of pure $\mathrm{PHB}$-diol starts at $128^{\circ} \mathrm{C}$ and completes at $227^{\circ} \mathrm{C}$ (Figure 5(a)). PUHE (Figure 5(b)) undergoes two-step thermal degradation with the first step occurring between 230 and $290^{\circ} \mathrm{C}$ and the second steps between 290 and $400^{\circ} \mathrm{C}$. It has been reported that the first weight loss is assigned to the degradation of PHB hard segments as a consequence of its relatively low thermal stability whereas the second weight loss is dominated by the thermal degradation of the PEG soft segments [42]. DTG curves show that the degradation velocity of PHB chain segment in copolymer was obviously lower than PHB-diol. It indicates that block-bonding between PHB-diol and PEG increases the thermal stability of PHB-diol. This is in accordance with the result of other PHB segmented copolymers.

3.9. Mechanics Performance Testing. Toughness is an important mechanical property for engineering polymers. Figure 7 gives the stress-strain curves of PUHE with different composition. The PUHE with different compositions are denoted as PUHE-25, PUHE-33, and PUHE-50 for PHB content with 25, 33 , and 50 , respectively.

As shown in Figure 7, PUHE-50, with a PEG content of $50 \%$, is brittle with a yield strength of $12.92 \mathrm{MPa}$ and elongation at break of only about $2.36 \%$. When PEG content increases to $67 \%$, the breaking strength of PUHE reaches as high as $20 \mathrm{MPa}$, with the elongation at break being about $210 \%$. The elongation at break and tensile strength of PUHE are markedly increased, which is mainly attributed to the regularity of $\mathrm{PHB}$ structure being broken and the crystallinity being declined. A certain amount of PEG plays internal plasticization role in the copolymer. At the same time, it is found that the fracture characteristic of PUHE is obviously transformed from brittleness into ductility with a gradual 


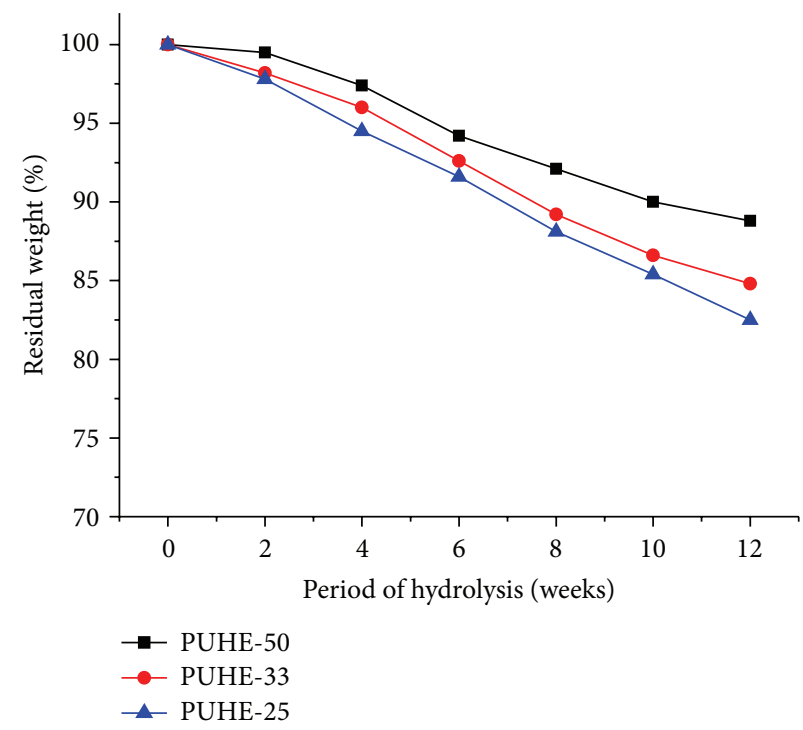

FIgURE 8: Residual weight (\%) of the PUHE films after degradation.
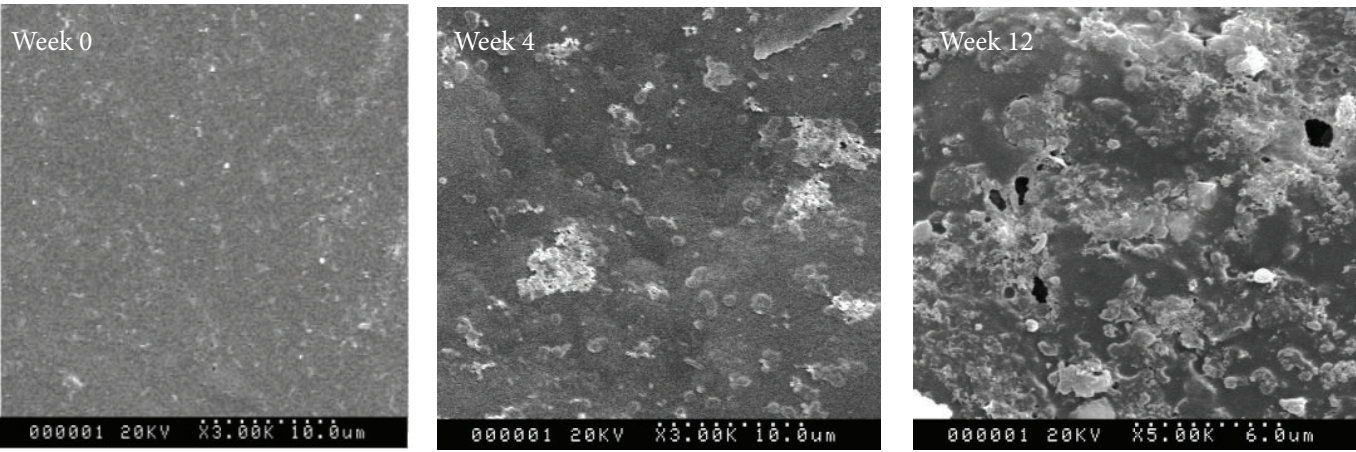

FIGURE 9: SEM micrographs of PUHE-50 film at various stages of degradation at pH 7.4.

increase in PEG content. When polyethylene glycol content increases to $75 \%$, the matrix gives priority to polyethylene glycol and the mechanical strength and elongation at break are substantially decreased.

3.10. Degradation Investigation. A degradation study was carried out using the solution-cast films submerged in phosphate buffer solution at $37^{\circ} \mathrm{C}$. The residual weights of the selected polymers prior to and after hydrolysis were studied (Figure 8). A linear decrease in the residual weight of the PUHE films was observed from week 2 onwards with a final weight loss of about $10 \sim 15 \%$ by 12 weeks of degradation. Compared with degradation profiles of samples PUHE-50 and PUHE-25, the former showed a slower degradation rate in the investigated period. Polymer PUHE-25, containing $75 \mathrm{wt} \%$ PEG in hydrolytic degradation, recorded the most dramatic decrease in physical weight of the polymer film, revealing that the strong polymer hydrophilicity was in favor of faster degradation [43]. As expected, the copolymers erosion could be controlled by adjusting the PHB/PEG ratios.
3.11. SEM Analysis of Film after Hydrolysis. The morphology of PUHE films degraded in PBS was observed by SEM. It was shown that degradation occurred gradually from the surface to the inside. A surface morphology change accompanied with structural deterioration of the film and an increase in porosity and cracks were observed throughout the course of degradation lasting over 12 weeks. A PUHE-50 showed greater hydrolytic stability to degradation probably due to the higher $\mathrm{PHB}$ content in the copolymer preventing the entry of the hydroxyl and water molecules (Figure 9) [40]. A PUHE-25 film presented with more extensive cracks and network structures in progressive weeks, suggesting extensive degradation (Figure 10).

\section{Conclusion}

The telechelic PHB with hydroxyl groups at both chain ends was successfully prepared by alcoholysis of PHB in the presence of $p$-toluenesulfonic acid as catalyst. The molecular weight was decreased by almost two orders of magnitude of 

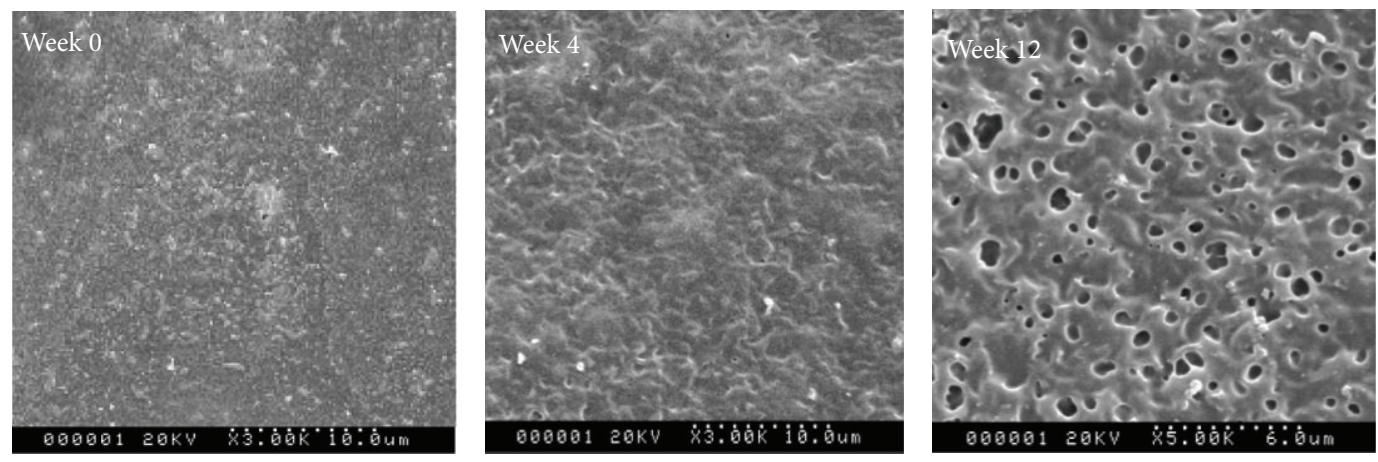

FIGURE 10: SEM micrographs of PUHE-25 film at various stages of degradation at pH 7.4.

PHB. DSC results show that the melting temperature $\left(T_{m}\right)$ decreases with the molecular weight of PHB decreasing. The hydroxyl contents in PHB-diol are ranging from 1.36 to 1.99 (the molar ratio) as determined by nonaqueous titration, in good agreement with theoretical value. A series of novel biodegradable amphiphilic polyurethanes PUHE has been successfully synthesized through the coupling reaction between hydroxyl groups in PHB-diol and PEG. The chemical compositions have been investigated by ${ }^{1} \mathrm{H}$ NMR and FTIR. GPC analysis confirmed the complete reaction producing polyurethanes with relatively narrow molecular weight distributions. TGA curves indicate that blockbonding between PHB-diol and PEG increases the thermal stability of precursor. Tensile strength and elongation at break of PUHE could reach as high as $20 \mathrm{MPa}$ and $210 \%$, when the content of PHB in PUHE decreases to $33 \%$. It is shown that hydrolytic degradation of PUHE occurred gradually from the surface to the inside. PUHE containing $75 \mathrm{wt} \%$ PEG in hydrolytic degradation recorded the most dramatic decrease in physical weight of the polymer film. The in vitro hydrolysis of PUHE could be controlled by adjusting the PHB/PEG ratios. These properties indicate that PUHE can be used as a biodegradable thermoplastic elastomer.

\section{Competing Interests}

The authors declare that there is no conflict of interests regarding the publication of this paper.

\section{Acknowledgments}

The authors gratefully acknowledge the financial support from the National Natural Science Foundation of China (no. 81271008) (Grant no. 02-05-23-SF0003).

\section{References}

[1] S. Hiki, M. Miyamoto, and Y. Kimura, "Synthesis and characterization of hydroxy-terminated [RS]-poly(3-hydroxybutyrate) and its utilization to block copolymerization with L-lactide to obtain a biodegradable thermoplastic elastomer," Polymer, vol. 41, no. 20, pp. 7369-7379, 2000.
[2] G.-Q. Chen and Q. Wu, "The application of polyhydroxyalkanoates as tissue engineering materials," Biomaterials, vol. 26, no. 33, pp. 6565-6578, 2005.

[3] E. Hablot, S. Dharmalingam, D. G. Hayes, L. C. Wadsworth, C. Blazy, and R. Narayan, "Effect of simulated weathering on physicochemical properties and inherent biodegradation of PLA/PHA nonwoven mulches," Journal of Polymers and the Environment, vol. 22, no. 4, pp. 417-429, 2014.

[4] J. J. Bai, J. Dai, and G. Li, "Electrospun composites of $\mathrm{PHBV} /$ pearl powder for bone repairing," Progress in Natural Science: Materials International, vol. 25, no. 4, pp. 327-333, 2015.

[5] N. Le Moigne, M. Sauceau, M. Benyakhlef et al., "Foaming of poly(3-hydroxybutyrate-co-3-hydroxyvalerate)/organoclays nano-biocomposites by a continuous supercritical $\mathrm{CO}_{2}$ assisted extrusion process," European Polymer Journal, vol. 61, no. 1, pp. 157-171, 2014.

[6] A. A. Ol'Khov, A. L. Iordanskii, and T. P. Danko, "Morphology of poly(3-hydroxybutyrate)-polyvinyl alcohol extrusion films," Journal of Polymer Engineering, vol. 35, no. 8, pp. 765-771, 2015.

[7] J. P. Reddy, S. Ahankari, M. Misra, and A. Mohanty, "A new class of injection moulded structural biocomposites from PHBV bioplastic and carbon fibre," Macromolecular Materials and Engineering, vol. 298, no. 7, pp. 789-795, 2013.

[8] A. N. Hayati, H. R. Rezaie, and S. M. Hosseinalipour, "Preparation of poly(3-hydroxybutyrate)/nano-hydroxyapatite composite scaffolds for bone tissue engineering," Materials Letters, vol. 65, no. 4, pp. 736-739, 2011.

[9] S. G. Karpova, A. L. Iordanskii, M. V. Motyakin et al., "Structural-dynamic characteristics of matrices based on ultrathin poly(3-hydroxybutyrate) fibers prepared via electrospinning," Polymer Science Series A, vol. 57, no. 2, pp. 131-138, 2015.

[10] L. Z. Li, W. Huang, B. J. Wang, W. F. Wei, Q. Gu, and P. Chen, "Properties and structure of polylactide/poly (3-hydroxybutyrate-co-3-hydroxyvalerate) (PLA/PHBV) blend fibers," Polymer, vol. 68, pp. 183-194, 2015.

[11] S. Zhang, J. Y. Xin, L. L. Chen, and Y. Wang, "Biosynthesis of poly- $\beta$ - hydroxybutyrate as new material of food packing by various strains of methanotrophs from methane," Advanced Materials Research, vol. 183-185, pp. 924-928, 2011.

[12] S. F. Williams, S. Rizk, and D. P. Martin, "Poly-4-hydroxybutyrate (P4HB): a new generation of resorbable medical devices for tissue repair and regeneration," Biomedizinische Technik, vol. 58, no. 5, pp. 439-452, 2013. 
[13] G. C. Bazzo, E. Lemos-Senna, and A. T. N. Pires, "Poly(3hydroxybutyrate)/chitosan/ketoprofen or piroxicam composite microparticles: preparation and controlled drug release evaluation," Carbohydrate Polymers, vol. 77, no. 4, pp. 839-844, 2009.

[14] J. Bidone, A. P. P. Melo, G. C. Bazzo et al., "Preparation and characterization of ibuprofen-loaded microspheres consisting of poly(3-hydroxybutyrate) and methoxy poly (ethylene glycol)-b-poly (D,L-lactide) blends or poly(3-hydroxybutyrate) and gelatin composites for controlled drug release," Materials Science and Engineering C, vol. 29, no. 2, pp. 588-593, 2009.

[15] C. B. Packhaeuser, J. Schnieders, C. G. Oster, and T. Kissel, "In situ forming parenteral drug delivery systems: an overview," European Journal of Pharmaceutics and Biopharmaceutics, vol. 58, no. 2, pp. 445-455, 2004.

[16] J. Babinot, E. Renard, and V. Langlois, "Controlled synthesis of well defined poly(3-hydroxyalkanoate)s-based amphiphilic diblock copolymers using click chemistry," Macromolecular Chemistry and Physics, vol. 212, no. 3, pp. 278-285, 2011.

[17] Q. Liu, C. Wu, H. Zhang, and B. Deng, "Blends of polylactide and poly(3-hydroxybutyrate-co-3-hydroxyvalerate) with low content of hydroxyvalerate unit: morphology, structure, and property," Journal of Applied Polymer Science, vol. 132, no. 42, Article ID 42689, 2015.

[18] K. Huang, B. P. Lee, D. R. Ingram, and P. B. Messersmith, "Synthesis and characterization of self-assembling block copolymers containing bioadhesive end groups," Biomacromolecules, vol. 3, no. 2, pp. 397-406, 2002.

[19] A. Daga, A. Muraglia, R. Quarto, R. Cancedda, and G. Corte, "Enhanced engraftment of EPO-transduced human bone marrow stromal cells transplanted in a 3D matrix in nonconditioned NOD/SCID mice," Gene Therapy, vol. 9, no. 14, pp. 915-921, 2002.

[20] H. D. Qiu, D. D. Li, X. Chen et al., "Synthesis, characterizations, and biocompatibility of block poly(ester-urethane)s based on biodegradable poly(3-hydroxybutyrate-co-4-hydroxybutyrate) (P3/4HB) and poly(E-caprolactone)," Journal of Biomedical Materials Research Part A, vol. 101, no. 1, pp. 75-86, 2013.

[21] J. Heller, J. Barr, S. Y. Ng et al., "Development and applications of injectable poly(ortho esters) for pain control and periodontal treatment," Biomaterials, vol. 23, no. 22, pp. 4397-4404, 2002.

[22] S. P. Khanna and A. K. Srivastava, "Recent advances in microbial polyhydroxyalkanoates," Process Biochemistry, vol. 40, no. 2, pp. 607-619, 2005.

[23] T. X. Su, R. Zhang, J. J. Wang, W. Shao, and Y. Hu, "Study on the poly(3-hydroxybutyrate-co-4-hydroxybutyrate)-based composites toughened by synthesized polyester polyurethane elastomer," Journal of Applied Polymer Science, vol. 132, no. 44, Article ID 42740, 2015.

[24] G. R. Saad and H. Seliger, "Biodegradable copolymers based on bacterial Poly((R)-3-hydroxybutyrate): thermal and mechanical properties and biodegradation behaviour," Polymer Degradation and Stability, vol. 83, no. 1, pp. 101-110, 2004.

[25] F. Ravenelle and R. H. Marchessault, "One-step synthesis of amphiphilic diblock copolymers from bacterial poly([R]-3hydroxybutyric acid)," Biomacromolecules, vol. 3, no. 5, pp. 1057-1064, 2002.

[26] Q. Zhao, G. Cheng, C. Song, Y. Zeng, J. Tao, and L. Zhang, "Crystallization behavior and biodegradation of poly(3hydroxybutyrate) and poly(ethylene glycol) multiblock copolymers," Polymer Degradation and Stability, vol. 91, no. 6, pp. 1240-1246, 2006.
[27] G. Y. Li, P. Li, H. D. Qiu, D. D. Li, M. Su, and K. T. Xu, "Synthesis, characterizations and biocompatibility of alternating block polyurethanes based on P3/4HB and PPG-PEG-PPG," Journal of Biomedical Materials Research Part A, vol. 98, no. 1, pp. 88-99, 2011.

[28] L. Vojtová, V. Kupka, J. Žídek, J. Wasserbauer, P. Sedláček, and J. Jančáŕ, "Biodegradable polyhydroxybutyrate as a polyol for elastomeric polyurethanes," Chemical Papers, vol. 66, no. 9, pp. 869-874, 2012.

[29] Y. Niu, Y. Zhu, R. Gao, W. Yu, L. Li, and K. Xu, "Synthesis, characterizations and biocompatibility of novel block polyurethanes based on poly(lactic acid) (PLA) and poly(3-hydroxybutyrateco-4-hydroxybutyrate) (P3/4HB)," Journal of Inorganic and Organometallic Polymers and Materials, vol. 25, no. 1, pp. 81-90, 2015.

[30] J. Brzeska, P. Dacko, K. Gębarowska et al., "The structure of novel polyurethanes containing synthetic poly[(R,S)-3hydroxybutyrate]," Journal of Applied Polymer Science, vol. 125, no. 6, pp. 4285-4291, 2012.

[31] W. F. Ou, H. D. Qiu, Z. F. Chen, and K. T. Xu, "Biodegradable block poly(ester-urethane)s based on poly(3-hydroxybutyrateco-4-hydroxybutyrate) copolymers," Biomaterials, vol. 32, no. 12, pp. 3178-3188, 2011.

[32] Z. F. Chen, S. T. Cheng, and K. T. Xu, "Block poly(esterurethane)s based on poly(3-hydroxybutyrate-co-4-hydroxybutyrate) and poly(3-hydroxyhexanoate-co-3-hydroxyoctanoate)," Biomaterials, vol. 30, no. 12, pp. 2219-2230, 2009.

[33] X. J. Loh, X. Wang, H. Li, X. Li, and J. Li, "Compositional study and cytotoxicity of biodegradable poly(ester urethane)s consisting of poly[(R)-3-hydroxybutyrate] and poly(ethylene glycol)," Materials Science and Engineering C, vol. 27, no. 2, pp. 267-273, 2007.

[34] X. J. Loh, S. H. Goh, and J. Li, "Hydrolytic degradation and protein release studies of thermogelling polyurethane copolymers consisting of poly[(R)-3-hydroxybutyrate], poly(ethylene glycol), and poly(propylene glycol)," Biomaterials, vol. 28, no. 28, pp. 4113-4123, 2007.

[35] S. H. S. Siqueira, R. C. L. Dutra, and M. F. Diniz, "Determination of NCO contents in polyurethane adhesives using MIR/NIR spectroscopies," Polimeros, vol. 18, no. 1, pp. 57-62, 2008.

[36] G. R. Saad, Y. J. Lee, and H. Seliger, "Synthesis and thermal properties of biodegradable poly(ester-urethane)s based on chemo-synthetic poly[(R,S)-3-hydroxybutyrate]," Macromolecular Bioscience, vol. 1, no. 3, pp. 91-99, 2001.

[37] T. D. Hirt, P. Neuenschwander, and U. W. Suter, “Telechelic diols from poly[(R)-3-hydroxybutyric acid] and poly[(R)-3-hydroxy butyric acid]-co-[(R)-3-hydroxyvaleric acid]," Macromolecular Chemistry and Physics, vol. 197, no. 5, pp. 1609-1614, 1996.

[38] T. D. Hirt, P. Neuenschwander, and U. W. Suter, "Synthesis of degradable, biocompatible, and tough blockcopolyesterurethanes," Macromolecular Chemistry and Physics, vol. 197, no. 12, pp. 4253-4268, 1996.

[39] X. Li, X. J. Loh, K. Wang, C. B. He, and J. Li, "Poly(ester urethane)s consisting of poly[(R)-3-hydroxybutyrate] and poly(ethylene glycol) as candidate biomaterials: characterization and mechanical property study," Biomacromolecules, vol. 6 , no. 5, pp. 2740-2747, 2005.

[40] X. J. Loh, K. K. Tan, X. Li, and J. Li, "The in vitro hydrolysis of poly(ester urethane)s consisting of poly[(R)-3hydroxybutyrate] and poly(ethylene glycol)," Biomaterials, vol. 27, no. 9, pp. 1841-1850, 2006. 
[41] X. M. Deng and J. Y. Hao, "Synthesis and characterization of poly(3-hydroxybutyrate) macromer of bacterial origin," European Polymer Journal, vol. 37, no. 1, pp. 211-214, 2001.

[42] H. F. Naguib, M. S. A. Aziz, and G. R. Saad, "Synthesis, morphology and thermal properties of polyurethanes nanocomposites based on poly(3-hydroxybutyrate) and organoclay," Journal of Industrial and Engineering Chemistry, vol. 19, no. 1, pp. 56-62, 2013.

[43] L. J. R. Foster and B. J. Tighe, "Centrifugally spun polyhydroxybutyrate fibres: accelerated hydrolytic degradation studies," Polymer Degradation and Stability, vol. 87, no. 1, pp. 1-10, 2005. 

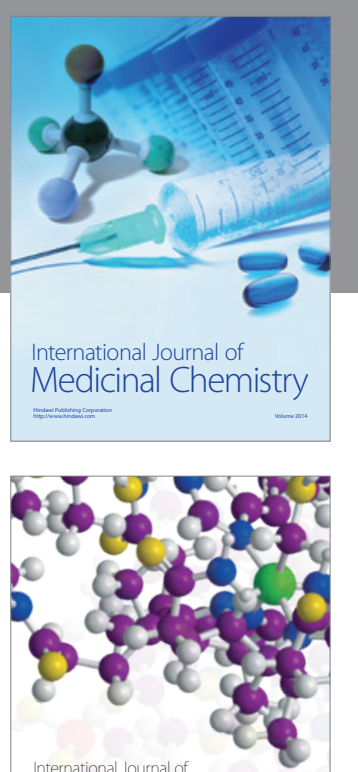

Carbohydrate Chemistry

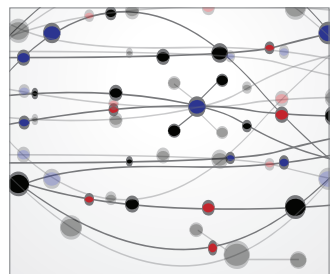

The Scientific World Journal
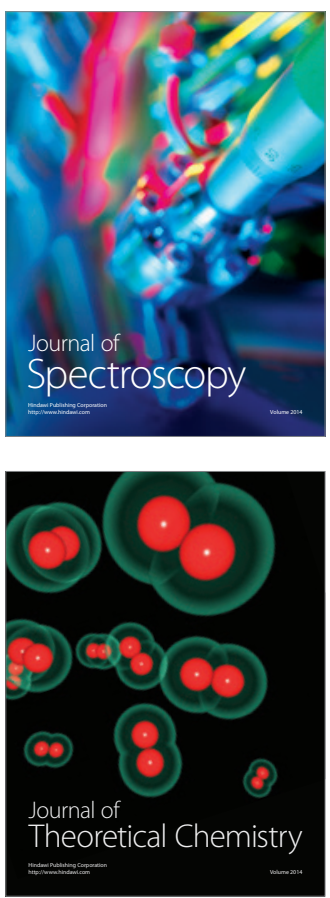
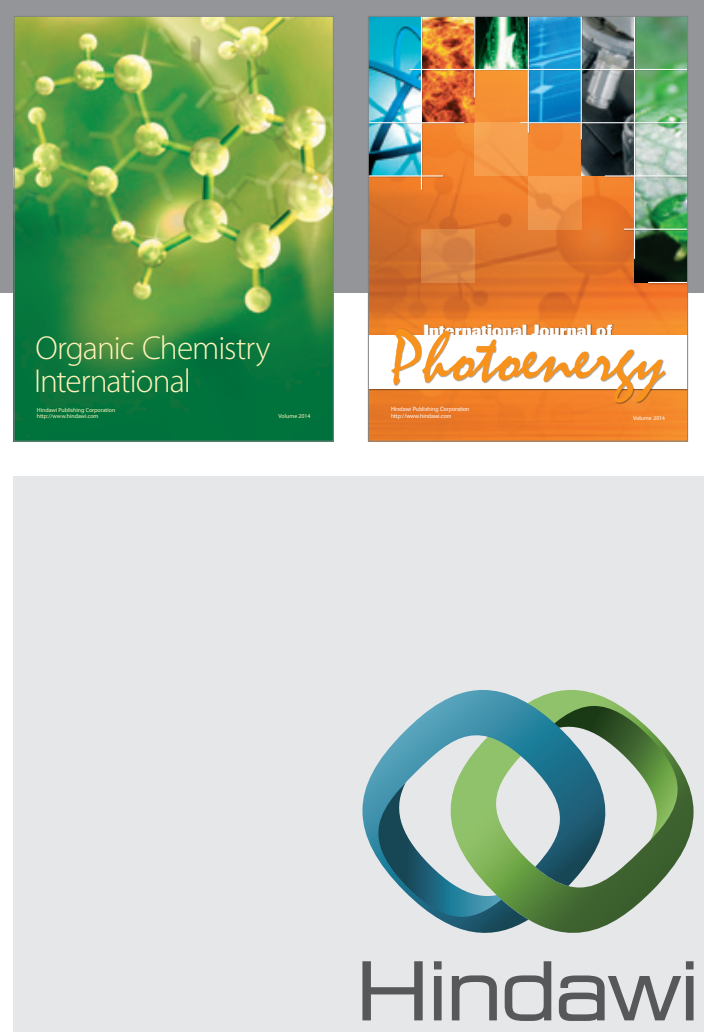

Submit your manuscripts at

http://www.hindawi.com

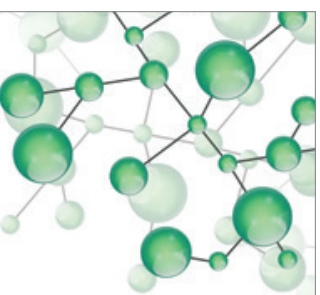

International Journal of

Inorganic Chemistry

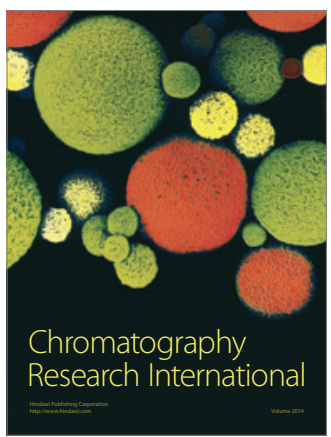

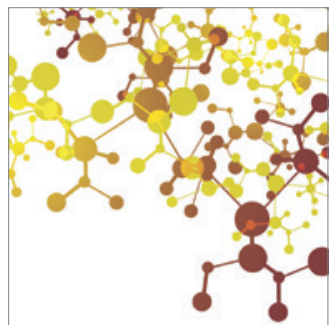

Applied Chemistry
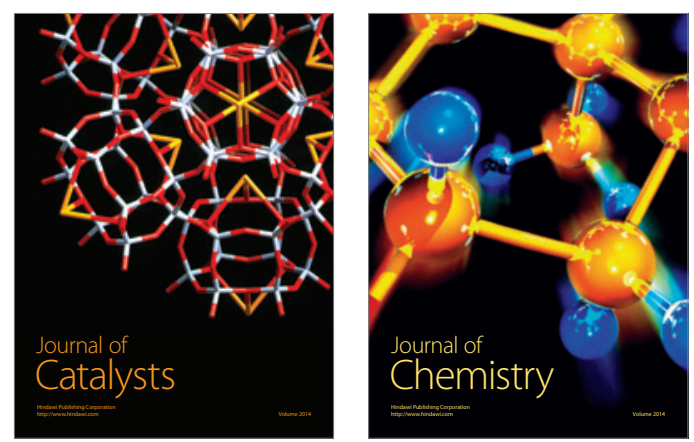
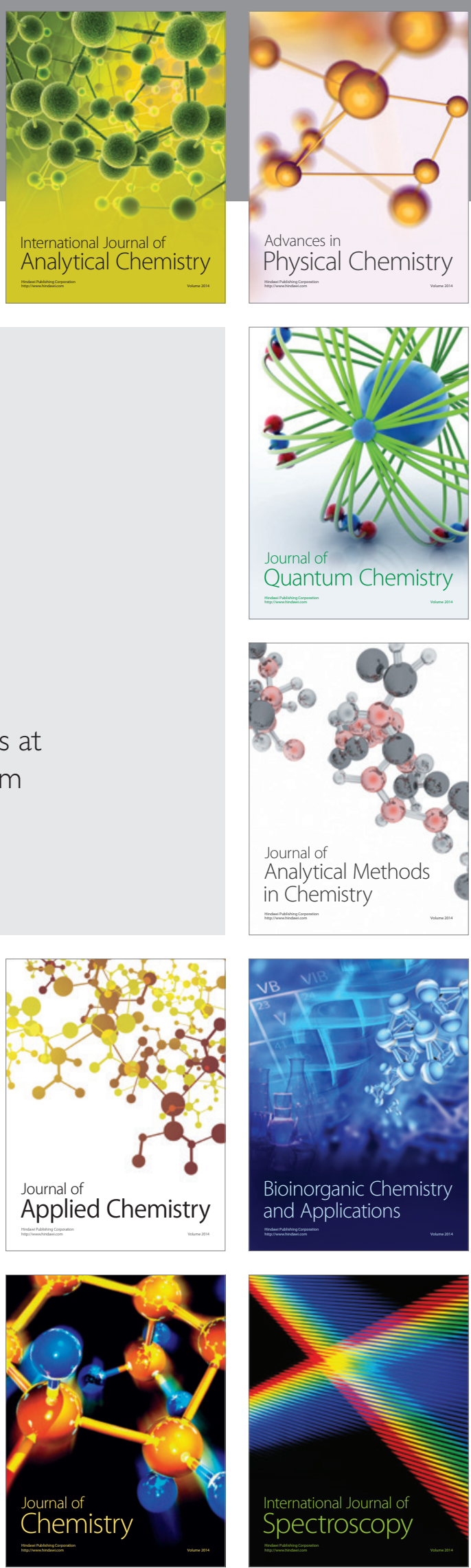